\title{
A CFD model for the frictional resistance prediction of antifouling coatings
}

\author{
Yigit Kemal Demirel $^{\text {a,*, }}$, Mahdi Khorasanchi ${ }^{\text {a }}$, Osman Turan ${ }^{\text {a }}$, Atilla Incecik ${ }^{\text {a }}$ and \\ Michael P. Schultz ${ }^{\text {b }}$
}
${ }^{a}$ Department of Naval Architecture, Ocean and Marine Engineering, University of Strathclyde, 100 Montrose Street, Glasgow, G4 0LZ, UK
${ }^{b}$ Department of Naval Architecture and Ocean Engineering, United States Naval Academy, Annapolis, Maryland, USA

*corresponding author; e-mail: yigit.demirel@strath.ac.uk, phone: +44(0)1415484275

\begin{abstract}
The fuel consumption of a ship is strongly influenced by her frictional resistance, which is directly affected by the roughness of the hull's surface. Increased hull roughness leads to increased frictional resistance, causing higher fuel consumption and $\mathrm{CO}_{2}$ emissions. It would therefore be very beneficial to be able to accurately predict the effects of roughness on resistance. This paper proposes a Computational Fluid Dynamics (CFD) model which enables the prediction of the effect of antifouling coatings on frictional resistance. It also outlines details of CFD simulations of resistance tests on coated plates in a towing tank. Initially, roughness functions and roughness Reynolds numbers for several antifouling coatings were evaluated using an indirect method. Following this, the most suitable roughness function model for the coatings was employed in the wall-function of the CFD software. CFD simulations of towing tests were then performed and the results were validated against the experimental data given in the literature. Finally, the effects of antifouling coatings on the frictional resistance of a tanker were predicted using the validated CFD model.
\end{abstract}

Keywords: Antifouling Coatings, Frictional Resistance, Computational Fluid Dynamics, Hull Roughness

\section{INTRODUCTION}

Hull resistance is of paramount importance to ships since it directly affects their speed, power requirements and fuel consumption. For this reason, reducing a ship's resistance is a fundamental requirement for naval architects, in order to benefit ship owners.

Ship resistance can be classified into two types; frictional resistance and residuary resistance. Frictional resistance can account for up to $80-85 \%$ of a ship's total resistance, particularly for merchant ships sailing at low speeds (van Manen and van Oossanen, 1988). As $95 \%$ of the world's cargo is transported by sea (RAEng, 2013), a means of reducing the frictional resistance of ships would dramatically reduce their fuel consumption, leading to reduced carbon emissions worldwide. The best method to reduce frictional resistance is to apply a treatment to a ship's hull, to minimise its physical and biological roughness. Physical roughness can be minimised by applying some preventative measures, but biological roughness (fouling) is more difficult to control. Fouling begins to occur immediately after a ship is immersed in water, and will continue to occur throughout a ship's life at sea until a cleaning process is performed. The level of fouling depends on several factors, including the length of time spent at sea, the water temperature, the geographical location of the ship, surface conditions and the salinity of the sea. The longer the ship's immersion time, the 
greater the level of fouling. Such fouling is responsible for a dramatic increase in a ship's frictional resistance.

Fouling causes surface roughness, resulting in an increase in a ship's frictional resistance and fuel consumption (Kempf, 1937). Milne (1990) stated that the fuel consumption may increase by up to $40 \%$, unless any precautions are taken to prevent fouling. According to Taylan (2010), the increase in resistance due to microorganism fouling is around 1-2\%, whereas an accumulation of hard shelled organisms may cause an increase in resistance of $40 \%$. Schultz (2007) investigated the effect of fouling on the required shaft power for a frigate at a speed of 15 knots. He found that the presence of slime alone required a $21 \%$ increase in shaft power, compared to an otherwise identical slime-free frigate, whereas heavy calcareous fouling led to an $86 \%$ increase in shaft power requirements.

The use of marine antifouling coatings is a common method used to smooth hull surfaces to reduce the frictional resistance and fuel consumption of a ship. Additionally, the use of coatings with a proper cathodic protection system can offer effective corrosion protection (Tezdogan and Demirel, 2014). However, such coatings will have initial surface roughnesses which affect a ship's frictional resistance. A means of assessing the effect of such a coating on frictional resistance would therefore be of great benefit. However, at present, there is no accurate method available to predict the effect of ship roughness due to the use of antifouling coatings (ITTC, 2005; 2011a).

An early review of studies investigating the effect of roughness on frictional resistance was performed by Lackenby (1962). Recently, Demirel et al. (2013b) demonstrated the importance of antifouling coatings with regards to ship resistance and powering. Different coatings result in different levels of fouling, meaning varying levels of hull roughness are seen for the same immersion time. A variety of coatings were therefore evaluated with regards to hull roughness after a specific time, and predictions of the increase in effective power for an LNG carrier were made. Schultz $(2004,2007)$ investigated the effects of several coatings' roughness and fouling on ship resistance and powering, and Candries et al. (2003) examined the effect of antifoulings on cylindrical surfaces and flat plates. Candries (2001) compared the drag, boundary layer and roughness characteristics of two coatings.

Khor and Xiao (2011) investigated the effects of fouling and two antifouling coatings on the drag of a foil and a submarine by employing a Computational Fluid Dynamics (CFD) method. They used the equivalent sand grain roughness height and the built-in wall-function which considers the uniform sand-grain roughness function model proposed by Cebeci and Bradshaw (1977), based on Nikuradse's data (1933). Currently, the ITTC (2011b) is still questioning the validity of the roughness model and equivalent sand grain roughness used in CFD applications for hull roughness, since it is known that the built-in roughness function model is based on uniform, closely packed sand roughness, whereas the roughness functions of real engineering surfaces do not show this behaviour. Izaguirre-Alza et al. (2010) also conducted experiments with plates coated with two different coatings. They used the CFD software package STAR-CCM+ to simulate their experiments and validate the roughness feature of the software. Although the comparison shows a very good agreement between the experimental data and the evaluated results, there is no evidence of the use of a specific roughness function model, rather than the built-in roughness function. Leer-Andersen and Larsson (2003), on the other hand, employed roughness functions in a commercial CFD code and predicted the skin friction of full scale ships. However, they used a specific module of the software and the study does not include RANS calculations. Date and Turnock (1999) demonstrated the required techniques to predict the skin friction of flat plates using RANS 
solvers and also showed that the effect of surface roughness on skin friction can be predicted using CFD software.

To the best of our knowledge, no specific CFD model exists to predict the effects of a marine antifouling coating's roughness on flow and frictional resistance. The aim of the present study is therefore to fill this gap by employing a modified wall-function in the CFD software. The proposed approach enables the prediction of the frictional resistance coefficients of coated plates for different speeds, using only roughness measurements of the surfaces. This model will also be a solid basis for a CFD model for the prediction of the effect of fouling on frictional resistance.

In this study, the experimental data of Schultz (2004) were used to establish the most suitable roughness function model for coatings. The required quantities were evaluated from the experimental data using an indirect method, and a roughness function model and roughness length scale were determined for coatings. This roughness function model was then employed in the wall-function of the CFD software package STAR-CCM+.

Following this, a validation study was performed through CFD simulations of towing tests involving coated plates at three Reynolds numbers $\left(2.8 \times 10^{6}, 4.2 \times 10^{6}\right.$ and $\left.5.5 \times 10^{6}\right)$, in a similar manner to the experiments of Schultz (2004), using STAR-CCM+. Frictional resistance coefficients and roughness Reynolds numbers were computed and compared with the experimental data. It should also be borne in mind that CFD simulations performed in this study are similar in part to those performed by Demirel et al. (2013a, 2014). However, these were exploratory studies and the simulations were performed at only one towing speed. Additionally, within the present study, improvements were made to the simulations to ensure their reproducibility.

It is important to note that the investigation was carried out using flat plates, based on the major assumption of Froude, which proposes that the skin friction of a hull is equal to that of a flat plate of the same length and area as the wetted surface of the ship (Lackenby, 1962). It is therefore convenient to choose a flat plate, as the surface roughness affects only the skin friction of a ship.

After the validation study, the effect of antifouling coatings on the frictional resistance of a tanker was predicted using the developed CFD model. A flat plate of length $170 \mathrm{~m}$ was chosen to represent a handymax tanker. Different types of antifouling coatings were considered at an operational ship speed of 13 knots. The plate was fully submerged since the surface roughness does not affect the wave-making resistance. Frictional resistance coefficients of the plate were evaluated for each case.

This paper is organised as follows: in Section 2, brief theoretical information is given about the turbulent boundary layer and about roughness effects on the velocity profile in the turbulent boundary layer. A determination of the appropriate roughness function model for antifouling coatings is presented in Section 3, while a new wall-function formulation is proposed and details of the CFD simulations are covered in Section 4. In Section 5, the numerical results and the experimental data are compared, and predictions of the increase in the frictional resistance coefficients of a tanker coated with different antifouling coatings are demonstrated. Finally, the results of the study are discussed in Section 6, along with recommendations for future avenues of research. 


\section{BACKGROUND}

\subsection{The turbulent boundary layer}

The turbulent boundary layer concept is essential in order to understand and assess the flow around a ship, since a turbulent boundary layer occurs around a ship when she is in motion.

If a flat plate is taken as an example, the flow is laminar at the first portion of the plate. As the flow continues across the plate, it becomes more and more turbulent in the transition region, until it eventually becomes a turbulent flow. The length of the transition region can vary due to several factors including surface roughness, pressure and velocity fluctuations (Candries, 2001). Figure 1 shows the typical development of a turbulent boundary layer over a flat surface (Cortana, 2013).

The turbulent boundary layer is assumed to consist of two main regions: an inner region and an outer region. The flow in the inner region is affected by surface conditions, such as roughness, whilst the flow in the outer region is not affected by such conditions.

The inner region is composed of a viscous sublayer and a log-law region. The mean average velocity in this region depends upon wall shear stress, the density of the fluid, kinematic viscosity and the distance from the wall.

The non-dimensional mean velocity profile can be expressed by the law of the wall, given by Eq 1

$U^{+}=f\left(y^{+}\right)$

where $U^{+}$is the non-dimensional velocity in the boundary layer and $y^{+}$is the non-dimensional normal distance from the boundary. These terms are further defined in $\mathrm{Eq} 2$ and $\mathrm{Eq} 3$, respectively.

$$
\begin{aligned}
U^{+} & =\frac{U}{U_{\tau}} \\
y^{+} & =\frac{y U_{\tau}}{v}
\end{aligned}
$$

where $U$ is the mean velocity, $U_{\tau}$ is the friction velocity defined as $\sqrt{\tau_{w} / \rho}, y$ is the normal distance from the boundary, $v$ is kinematic viscosity, $\tau_{\mathrm{w}}$ is shear stress magnitude and $\rho$ is the density of the fluid.

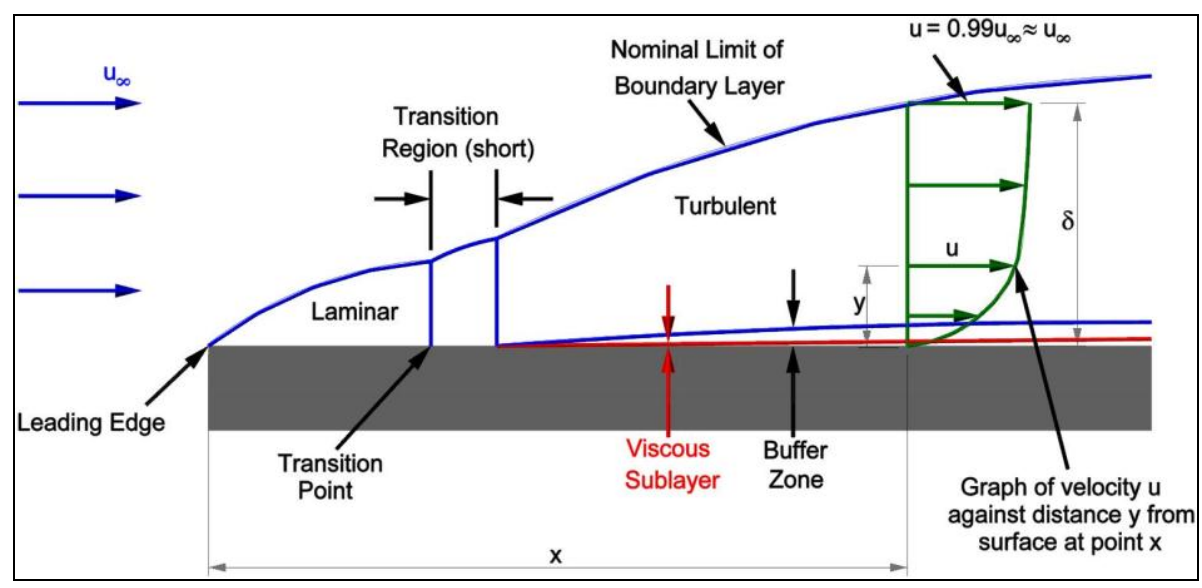

Figure 1. The development of a turbulent boundary layer over a flat surface (Cortana, 2013). 
The viscous sublayer consists of a linear sublayer and a buffer layer. As the name suggests, the velocity profile is linear in the linear sublayer, given by Eq 4.

$U^{+}=y^{+}$

In the buffer layer, the velocity profile begins to deflect from linearity. In the log-law region, a velocity profile for smooth surfaces was suggested as shown in Eq 5 (Millikan, 1938)

$U^{+}=\frac{1}{\kappa} \ln y^{+}+B$

where $\kappa$ is the von Karman constant and $B$ is the smooth wall log-law intercept. The velocity profile in a typical turbulent boundary layer is shown in Figure 2 (Schultz and Swain, 2000).

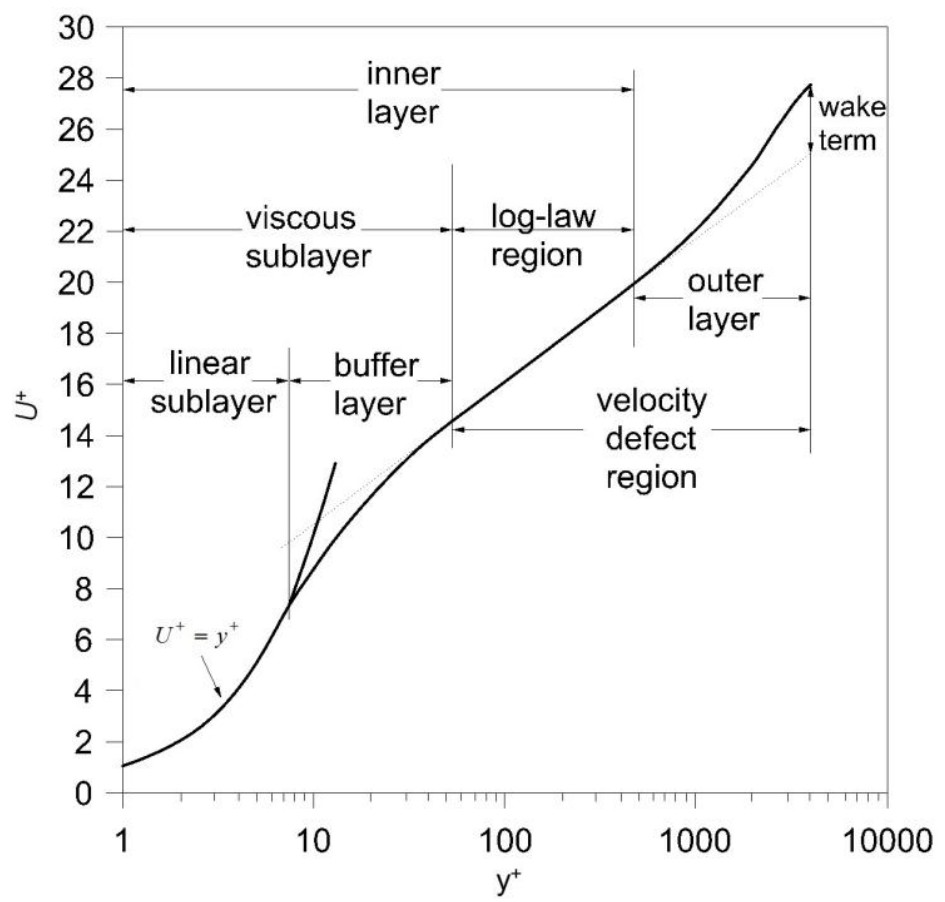

Figure 2. Velocity profile in a turbulent boundary layer, adapted from Schultz and Swain (2000).

\subsection{The effect of roughness on the turbulent boundary layer}

Surface roughness leads to an increase in turbulence, which means that the turbulent stress and wall shear stress increase. Ultimately, the velocity in the turbulent boundary layer decreases.

Although roughness can be described using various parameters, the key parameter is thought to be the roughness height, $k$, or equivalent sand roughness height, $k_{\mathrm{s}}$. The roughness height can be normalised and termed the roughness Reynolds number, given by Eq 6 .

$k^{+}=\frac{k U_{\tau}}{v}$

The flow over a surface is generally classified with respect to the roughness Reynolds number, i.e. as a hydraulically smooth regime, a transitionally rough regime or a fully rough regime. However, it should be noted that different roughness types may generate different 
flow regimes on surfaces even if the same roughness Reynolds number is recorded (Schultz, 2007).

The law of the wall in the inner region changes in the presence of surface roughness. The velocity in the inner region of the turbulent boundary layer over a rough surface becomes a function of $y^{+}$and $k^{+}$, given by Eq 7 (Schubauer and Tchen, 1961).

$U^{+}=f\left(y^{+}, k^{+}\right)$

The effect of roughness on flow can also be observed on the velocity profile (Schultz and Swain, 2000). Roughness causes a decrease in the log-law velocity profile (termed the roughness function) shown as $\Delta U^{+}$. The roughness function in the velocity profile due to roughness is depicted in Figure 3 (Schultz and Swain, 2000). The log-law velocity profile for rough surfaces in the turbulent boundary layer is given by Eq 8

$U^{+}=\frac{1}{\kappa} \ln \left(y^{+}\right)+B-\Delta U^{+}$

in which $\Delta U^{+}$is the roughness function. It should also be considered that the decrease in velocity profile manifests itself as an increase in the frictional resistance.

$\Delta U^{+}$values are typically obtained experimentally, since there is no universal roughness function model for every kind of roughness.

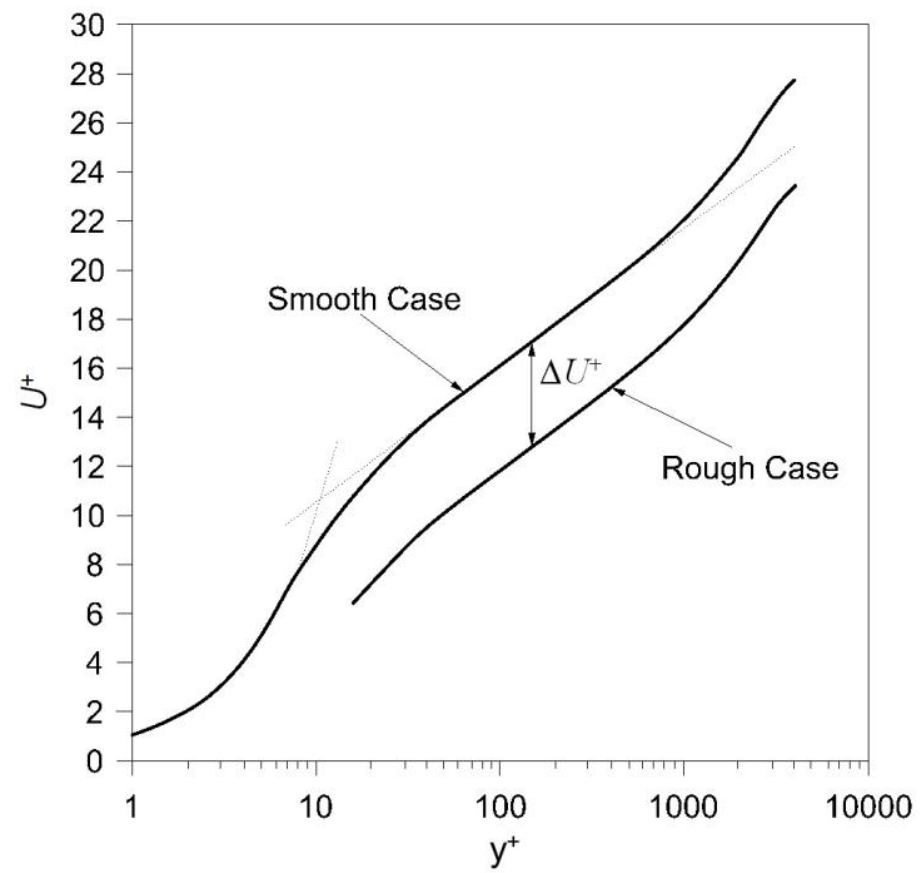

Figure 3. The roughness effect on log-law velocity profile, adapted from Schultz and Swain (2000). 


\section{ROUGHNESS FUNCTIONS}

Schultz (2004) conducted towing tests of flat plates coated with different antifouling coatings in order to investigate the initial drag performances of the coatings. He used five antifouling coating systems: Silicone 1, Silicone 2, Ablative Copper, SPC (Self-Polishing Copolymer) Copper and SPC TBT (Tributyltin). Three control surfaces were also tested: the plates covered with 60-grit and 220-grit sandpapers (SP) and a smooth surface. The frictional resistance coefficients of each test surface were obtained for seven different Reynolds numbers.

Roughness amplitude parameters of all test surfaces are shown in Table $1 . R_{a}$ is the average roughness height, $R_{q}$ is the root mean square average of the roughness profile ordinates and $\mathrm{R}_{\mathrm{t}}$ is the maximum peak to trough roughness height.

Table 1. Roughness amplitude parameters for all test surfaces, adapted from Schultz (2004).

\begin{tabular}{lccc}
\hline Test Surface & $\mathrm{R}_{\mathrm{a}}(\mu \mathrm{m})$ & $\mathrm{R}_{\mathrm{q}}(\mu \mathrm{m})$ & $\mathrm{R}_{\mathrm{t}}(\mu \mathrm{m})$ \\
\hline Silicone 1 & $12 \pm 2$ & $14 \pm 2$ & $66 \pm 7$ \\
Silicone 2 & $14 \pm 2$ & $17 \pm 2$ & $85 \pm 8$ \\
Ablative Copper & $13 \pm 1$ & $16 \pm 1$ & $83 \pm 6$ \\
SPC Copper & $15 \pm 1$ & $18 \pm 1$ & $97 \pm 10$ \\
SPC TBT & $20 \pm 1$ & $24 \pm 2$ & $129 \pm 9$ \\
60-grit SP & $126 \pm 5$ & $160 \pm 7$ & $983 \pm 89$ \\
220-grit SP & $30 \pm 2$ & $38 \pm 2$ & $275 \pm 17$ \\
\hline
\end{tabular}

$k^{+}$and $\Delta U^{+}$for the surfaces were obtained iteratively using Eq 9 and 10 (Granville, 1987) using the experimental data

$$
\begin{aligned}
& k^{+}=\left(\frac{k}{L}\right)\left(\frac{\mathrm{R}_{e L} C_{F}}{2}\right)\left(\sqrt{\frac{2}{C_{F}}}\right)_{R}\left[1-\frac{1}{\kappa}\left(\sqrt{\frac{C_{F}}{2}}\right)_{R}+\frac{1}{\kappa}\left(\frac{3}{2 \kappa}-\Delta U^{+}\right)\left(\frac{C_{F}}{2}\right)_{R}\right] \\
& \Delta U^{+}=\left(\sqrt{\frac{2}{C_{F}}}\right)_{S}-\left(\sqrt{\frac{2}{C_{F}}}\right)_{R}-19.7\left[\left(\sqrt{\frac{C_{F}}{2}}\right)_{S}-\left(\sqrt{\frac{C_{F}}{2}}\right)_{R}\right]-\frac{1}{\kappa} \Delta U^{+}\left(\sqrt{\frac{C_{F}}{2}}\right)_{R}
\end{aligned}
$$

where $L$ is the plate length, $\mathrm{R}_{\mathrm{eL}}$ is the plate Reynolds number, $\mathrm{C}_{F}$ is the frictional drag coefficient, $\Delta U^{+}$is the roughness function slope and the subscript $\mathrm{S}$ indicates a smooth condition whereas the subscript $\mathrm{R}$ indicates a rough condition.

The selection of the roughness height is critical to define a roughness function model, though the selected roughness height does not affect the roughness function value - it only affects the abscissa of the profile of roughness functions against roughness Reynolds numbers. For this reason, the roughness height can be selected such that the roughness function values fall on a pre-defined roughness function model, provided that the observed behaviours are still deemed appropriate relative to each other.

As per Schultz's (2004) suggestion, $0.17 \mathrm{R}_{\mathrm{a}}$ is chosen as the roughness height for antifouling surfaces, whereas the roughness height for sandpapers is chosen as $0.75 \mathrm{R}_{\mathrm{t}}$. Figure 4 depicts the evaluated roughness functions and roughness Reynolds numbers together with the roughness function models. 


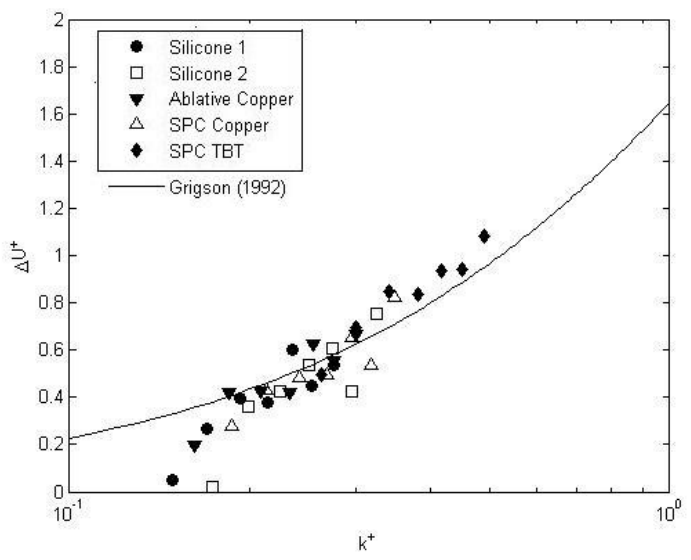

a)

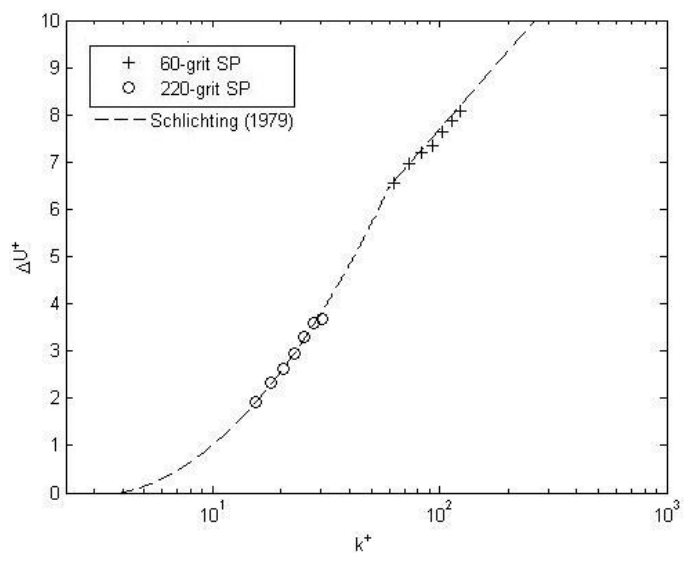

b)

Figure 4. Roughness functions vs. roughness Reynolds number for a) coatings, b) sandpapers.

It is evident from Figure 4 that the roughness functions for antifouling coatings are in good agreement with the Colebrook-type roughness function of Grigson (1992) using $k=0.17 \mathrm{R}_{\mathrm{a}}$, and the roughness functions for sandpapers show excellent agreement with Schlichting's (1979) uniform sand roughness function using $k=0.75 \mathrm{R}_{\mathrm{t}}$. It should be noted that these roughness heights and roughness function models were proposed by Schultz (2004). A piece of future work may be the investigation of the range of applicability of the selected roughness height for antifouling coatings.

As seen in Figure 4, different types of surfaces, such as antifouling coatings and sandpapers, show different roughness function behaviours, meaning different pre-defined roughness function models are appropriate for each type. For this reason, the selected roughness length scales may vary accordingly in order for them to fall on the corresponding model. This means that, the roughness function models and roughness heights selected in this study may not necessarily work for other surfaces and other roughness function models.

Although there are other roughness function models which are thought to be suitable for real engineering surfaces and fouling, such as the one described in Schultz and Flack (2007), the Colebrook-type roughness function of Grigson (1992) is appropriate when only antifouling coatings are taken into account. 


\section{NUMERICAL MODELLING}

\subsection{Mathematical formulation}

An Unsteady Reynolds-Averaged Navier-Stokes (URANS) method was used to solve the governing equations in this study. These mass and momentum conservation equations were solved by the commercial CFD software STAR-CCM+. The averaged continuity and momentum equations for incompressible flows are given in tensor notation and Cartesian coordinates by Eq 11 and Eq 12 (Ferziger and Peric, 2002)

$$
\begin{aligned}
& \frac{\partial\left(\rho \bar{u}_{i}\right)}{\partial x_{i}}=0, \\
& \frac{\partial\left(\rho \bar{u}_{i}\right)}{\partial t}+\frac{\partial}{\partial x_{j}}\left(\rho \bar{u}_{i} \bar{u}_{j}+\rho \overline{u_{i}^{\prime} u_{j}^{\prime}}\right)=-\frac{\partial \bar{p}}{\partial x_{i}}+\frac{\partial \bar{\tau}_{i j}}{\partial x_{j}}
\end{aligned}
$$

where $\rho$ is density, $\bar{u}_{i}$ is the averaged Cartesian components of the velocity vector, $\rho \overline{u_{i}^{\prime} u_{j}^{\prime}}$ is the Reynolds stresses and $p$ is the mean pressure. $\bar{\tau}_{i j}$ are the mean viscous stress tensor components, as shown in Eq 13

$$
\bar{\tau}_{i j}=\mu\left(\frac{\partial \bar{u}_{i}}{\partial x_{j}}+\frac{\partial \bar{u}_{j}}{\partial x_{i}}\right)
$$

in which $\mu$ is the dynamic viscosity.

The solver uses a finite volume method which discretises the governing equations. A second order convection scheme was used for the momentum equations and a first order temporal discretisation was used. The flow equations were solved in a segregated manner. The continuity and momentum equations were linked with a predictor-corrector approach.

The SST (Shear Stress Transport) k- $\omega$ turbulence model was used in order to complete the RANS equations, which blends the k- $\omega$ model near the wall and the k- $\varepsilon$ model in the far field. The Volume of Fluid (VOF) method was used to model and position the free surface, in cases where a free surface was present. In this study, the Courant-Frederich-Lewis (CFL) number was always held at values less than unity to ensure the numerical stability.

\subsection{Wall-Function approach for antifouling coatings}

Wall functions are mathematical expressions which are used to link the viscosity affected region between the wall and log-law region (ANSYS, 2011). This approach assumes that the near wall cell lies within the logarithmic region of the boundary layer. The standard wall functions used in this study impose standard wall laws which have discontinuities between the laminar and logarithmic regions. The velocity profiles of standard wall laws are given by Eq 14 (CD-ADAPCO, 2012):

$U^{+}=\left\{\begin{array}{lll}U_{\text {lam }}^{+} & \rightarrow & y^{+} \leq y_{m}^{+} \\ U_{\text {turb }}^{+} & \rightarrow & y^{+}>y_{m}^{+}\end{array}\right.$ 
where $U^{+}$is the wall-parallel velocity normalised with respect to $U_{\tau}, \mathrm{y}_{\mathrm{m}}^{+}$is the intersection of the viscous and fully turbulent regions, and the subscripts lam and turb indicate laminar and turbulent properties, respectively.

Given that roughness causes a downward shift in the velocity distribution in the log-law region, the mean velocity distribution is taken to be equivalent to the turbulent velocity profile from this point onward: $U^{+}=U_{\text {turb }}^{+}$. The log-law velocity profile is defined by Eq 15

$U^{+}=\frac{1}{\kappa} \ln \left(E^{\prime} y^{+}\right)$

where

$$
E^{\prime}=\frac{E}{f}
$$

in which $E$ is the wall function coefficient and $f$ is the roughness coefficient. $\kappa$ is taken to be 0.42 as suggested by Cebeci and Bradshaw (1977). For smooth flows, $f$ becomes unity, and $E$ was chosen such that Eq 5 is satisfied for $B=5.2$.

The coefficient $f$ is directly related to the roughness function and its value depends on the flow regime. $f$ is described by Eq 17 and Eq 18 (CD-ADAPCO, 2012). It is of note that the coefficient $f$ is an expanded version of the expression given by Cebeci and Bradshaw (1977)

$$
f=\left\{\begin{array}{cll}
1 & \rightarrow & k^{+}<k_{s m}^{+} \\
{\left[A\left(\frac{k^{+}-k_{s m}^{+}}{k_{r}^{+}-k_{s m}^{+}}\right)+C k^{+}\right]^{a}} & \rightarrow & k_{s m}^{+}<k^{+}<k_{r}^{+} \\
\mathrm{A}+C k^{+} & \rightarrow & k_{r}^{+}<k^{+}
\end{array}\right.
$$

where

$a=\sin \left[\frac{\pi \log \left(k^{+} / k_{s m}^{+}\right)}{2} \frac{\log \left(k_{r}^{+} / k_{s m}^{+}\right)}{]}\right.$

$k_{\text {sm }}^{+}$and $k_{\mathrm{r}}^{+}$designate smooth and rough roughness Reynolds number limits, respectively, in which the flow is hydraulically smooth for $k^{+}<k_{\mathrm{sm}}^{+}$and fully rough for $k^{+}>k_{\mathrm{r}}^{+}$. The model used by the software assumes that flow is occurring over uniform, closely packed sand as proposed by Cebeci and Bradshaw (1977), based on Nikuradse's data (1933), using the default values of $k_{\mathrm{sm}}^{+}=2.25$ and $k_{\mathrm{r}}^{+}=90$, and the coefficients $A=0$ and $C=0.253$. The proposed model in this paper, on the other hand, suggests that the wall law for antifouling coatings satisfies the mean velocity profile given by Eq 19.

$U^{+}=\frac{1}{\kappa} \ln \left(\frac{y^{+}}{1+k^{+}}\right)+B$

For this reason, only one roughness function model for coatings is proposed, since the roughness function behaviours of coatings can be represented by one simple model, as evidenced in Figure 4. $k^{+}{ }_{\mathrm{sm}}$ and ${k_{\mathrm{r}}^{+}}^{+}$are therefore chosen such that it is almost impossible for $k^{+}$to fall in the first two regimes - $k^{+}$is always greater than $k_{\mathrm{r}}^{+}$. The coefficients $A$ and $C$ are then chosen such that the roughness function model matches the Colebrook-type roughness function of Grigson (1992). $k=0.17 \mathrm{R}_{\mathrm{a}}$ is chosen for the surfaces coated with antifouling coatings. 


\subsection{Geometry and boundary conditions}

It is necessary to select appropriate boundary conditions for CFD problems, since these boundary conditions directly affect the accurate flow solutions. Two sets of boundary conditions are defined in this study, one for the validation study and the other for the full scale prediction study.

For the validation simulations, no-slip wall boundary conditions were applied to the bottom and wall of the domain because they represent the real bottom and wall of the towing tank used by Schultz (2004). Therefore the corresponding dimensions were chosen accordingly. The plate was also modelled as a no-slip rough wall in order to represent the roughness on the plate. The top of the domain, which represents air, was modelled as a wall with a slip condition applied to it. The two opposite faces at the x-direction of the domain, i.e. the lefthand face and right-hand face of the domain in the top view, were modelled as a velocity inlet and a pressure outlet, respectively. The symmetry plane, as the name implies, has a symmetry condition. Hence, only half of the plate and control volume were taken into account. This does not significantly affect the computations and it halves the required cell numbers.

For the full scale prediction simulations, it is assumed that the plate is completely submerged in an infinite ocean, since surface roughness only affects skin friction. Therefore, it is only necessary to model a quarter of the plate. The total number of cells and the required computational time is decreased by quartering the problem by means of defining two symmetry planes, with no compromise in accuracy. For this reason, the lower faces, both in the top view and profile view, were modelled as symmetry planes. The plate itself has a noslip rough wall condition to represent the roughness on the plate. The left-hand face and right-hand face of the domain in the top view were modelled as a velocity inlet and a pressure outlet, respectively. The rest was set up to be symmetrical in order to eliminate wall effects to as great a degree as possible.

The dimensions of the plate and the control volume, and the boundary conditions used, are shown in Figure 5 for the validation study and in Figure 6 for the full scale prediction study. The validation simulations are reproductions of the experiments given by Schultz (2004).

Another critical selection is the positioning of the boundaries, especially the downstream outlet boundary and the upstream inlet boundary. The inlet is placed at one plate length upstream and the outlet boundary is placed at two plate lengths downstream for the full scale predictions, to ensure the boundary independent solutions as per the findings of Date and Turnock (1999). The positions of the inlet and outlet boundaries are doubled for the validation study since there is a free surface in this case.

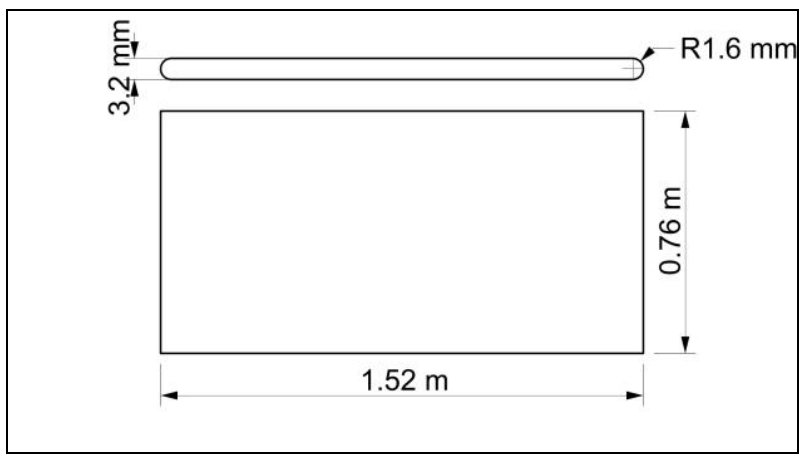

a) 


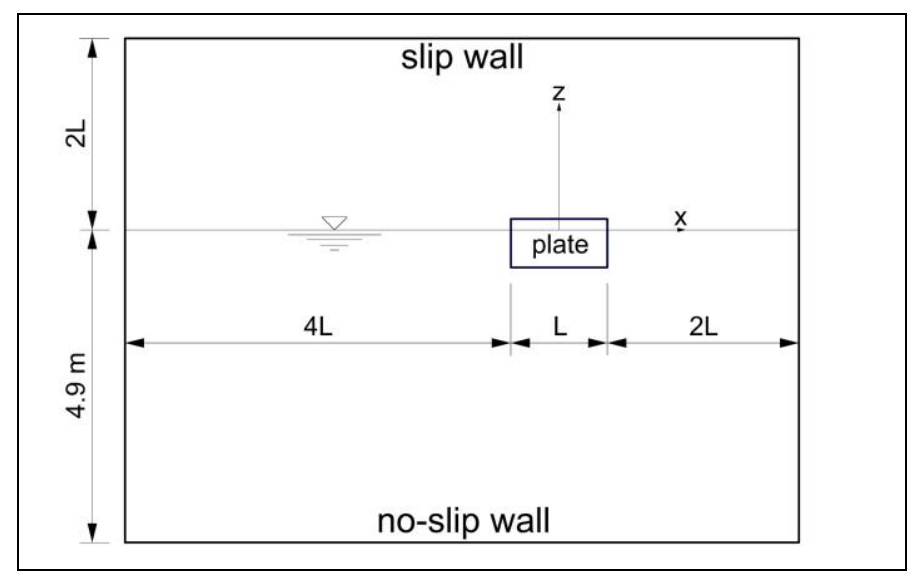

b)

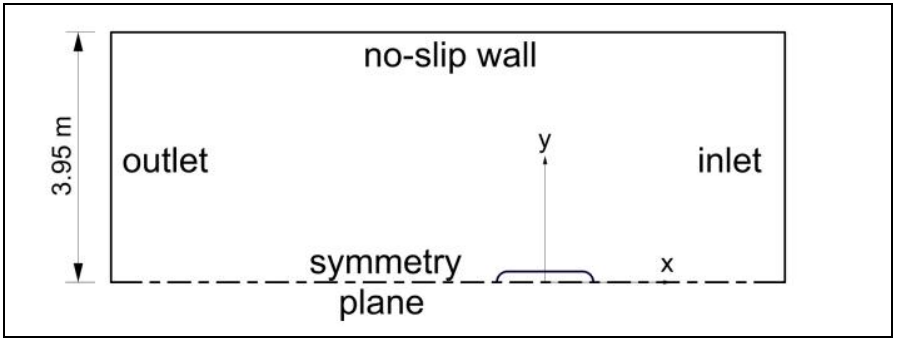

c)

Figure 5. a) The plate, b) profile view of the domain and c) top view of the domain, showing the dimensions and boundary conditions used for the validation study.

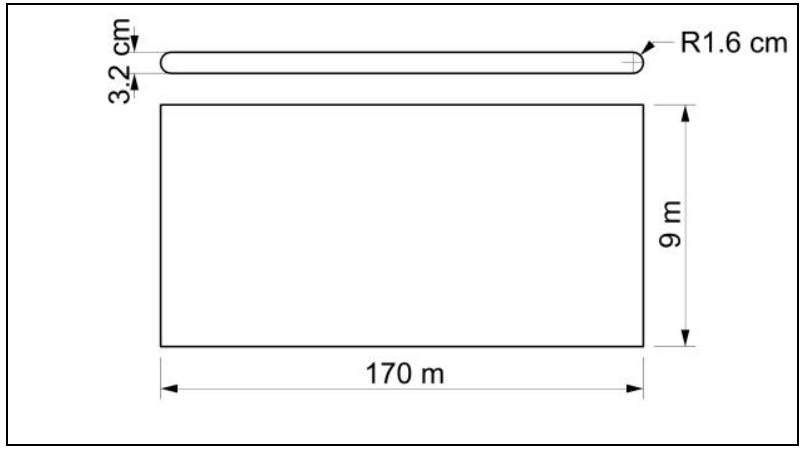

a)

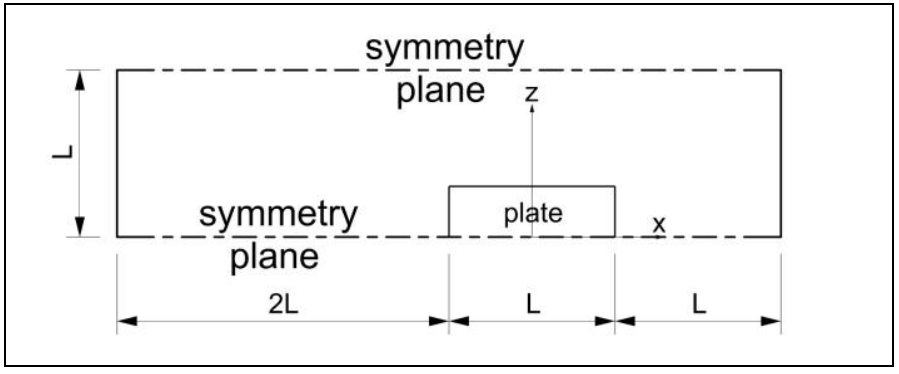

b) 


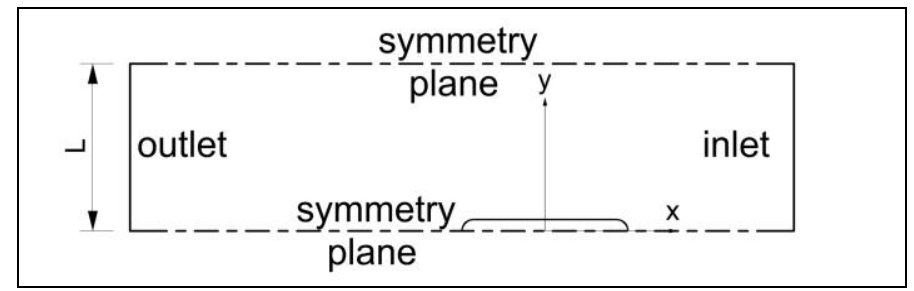

c)

Figure 6. a) The plate, b) profile view of the domain and c) top view of the domain, showing the dimensions and boundary conditions used for the full scale prediction study.

\subsection{Mesh generation}

A cut-cell grid with prism layer mesh on the walls was generated using the automatic mesh generator in STAR-CCM+. The plate was meshed separately to give a much finer grid, with additional refinement at the free surface. Refined meshes were generated in the area around the plate, as well as in the wake region, in order to accurately capture the flow properties for the validation study. A special near-wall mesh resolution was applied to all surfaces with the no-slip boundary condition. Details of the near-wall mesh generation are given in the following section.

A convergence test was carried out in order to obtain grid independent solutions, since the cell numbers are influential on the solution. It is of note that once the mesh independent solution is achieved, further refinement of the mesh does not affect the final solution, though it does affect the solution time. The full details and a discussion of the grid dependence tests are given in Section 5.1. As a result of the tests, in total, circa 4 million cells were generated for both the validation and prediction studies.

Figure 7 shows cross-sections of the meshed domain whereas Figure 8 shows a view of mesh configurations of the plate and the free surface. Figure 9 shows cross-sections of the meshed domain of the full scale prediction simulations. It is of note that the figures show the whole sections as if there is no symmetrical boundary owing to the visual transform feature of the software.

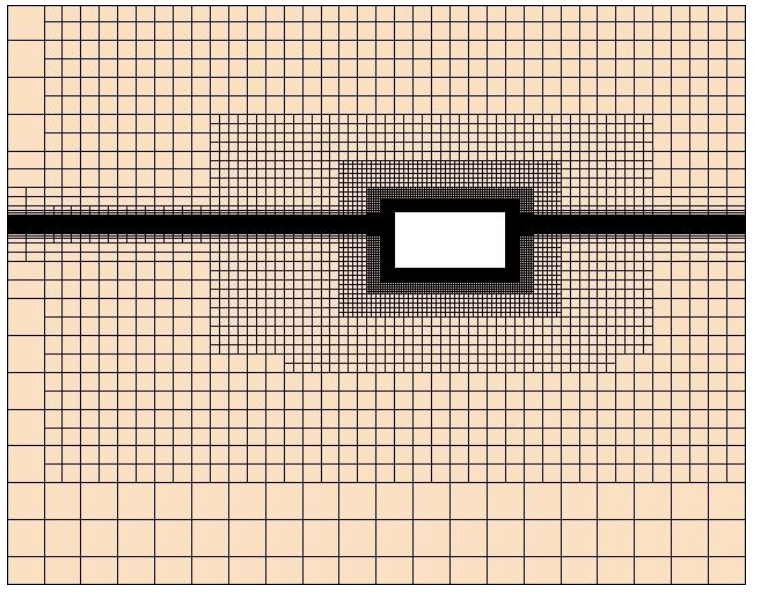

a)

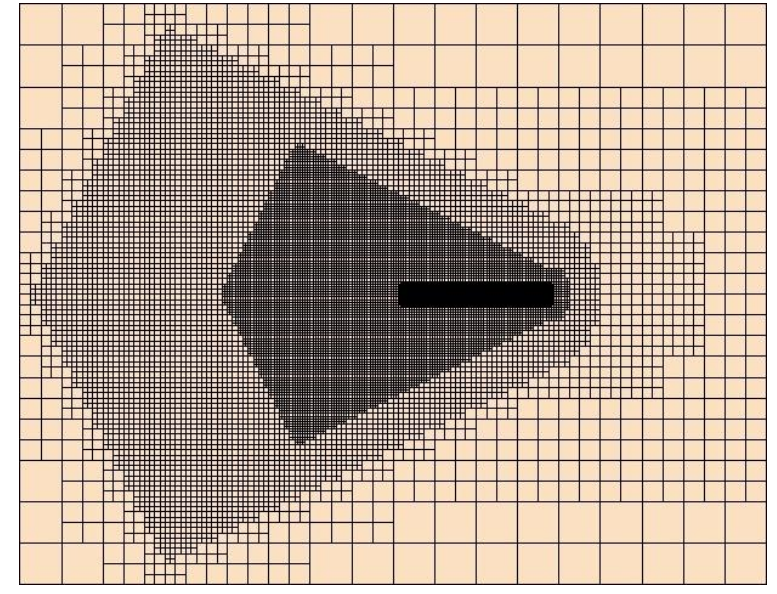

b)

Figure 7. a) Profile view cross-section b) top view cross-section of the domain. 


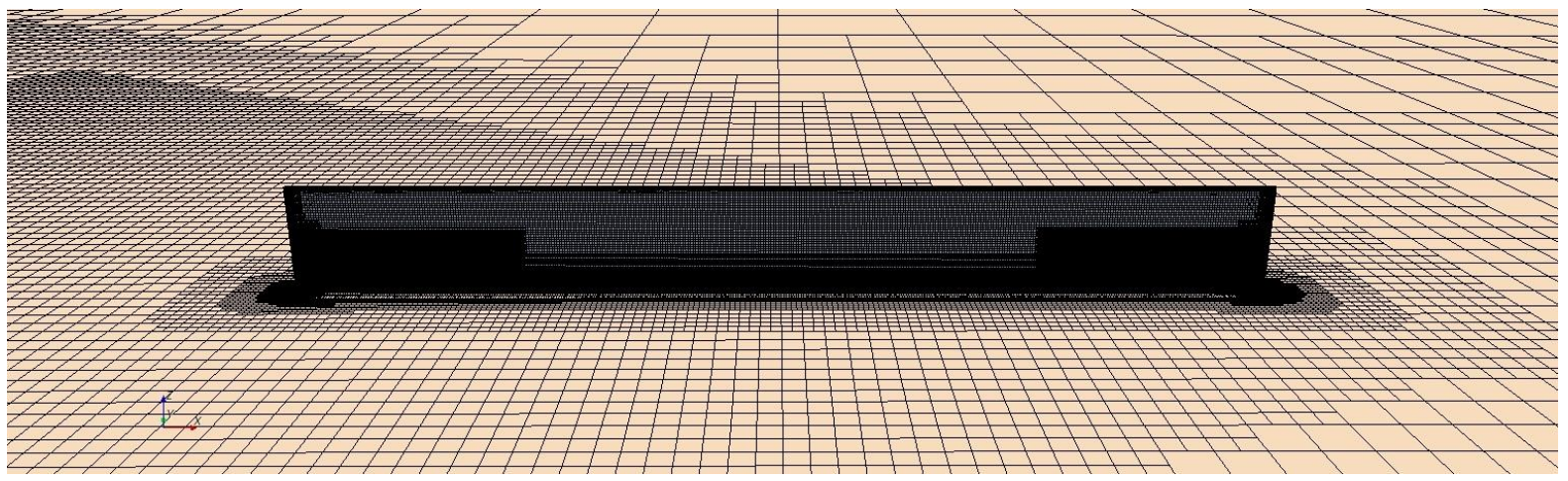

Figure 8. Mesh for the plate and free surface.

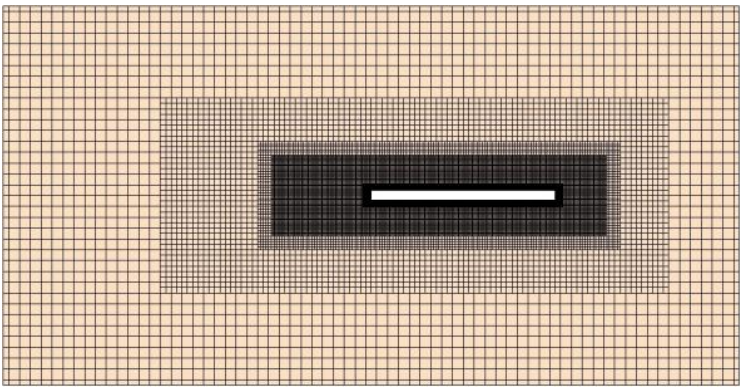

a)

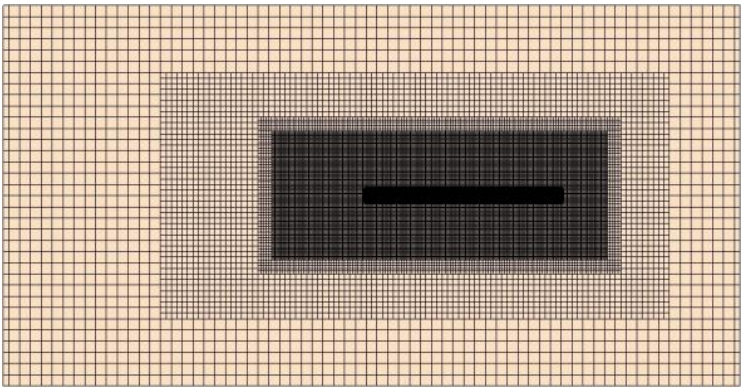

b)

Figure 9. a) Profile view cross-section b) top view cross-section of the domain.

\subsubsection{Near-wall mesh generation}

An important point is the selection of the prism layer thickness and the number of prism layers, since this represents the boundary layer of the wall. The prism layer thickness and the prism layer number determine the normal distance from the centroid to the wall in walladjacent cells. This distance is crucial to capture the gradients in the boundary layer and it should be selected with regards to the roughness height and required $y^{+}$values.

The prism layer thickness on all no-slip walls was set to the corresponding turbulent boundary layer thickness along the flat plate in question for each Reynolds number. Prism layer numbers were selected to ensure that the $y^{+}$value on the plate is maintained at a value greater than 30 in order to use standard wall laws for all Reynolds numbers. It is of note that the same prism layer numbers were used for all Reynolds numbers. In the prism layer mesh generation, a geometric progression with ratio 1.5 was used in all directions. A near wall mesh dependence study was carried out and the details and a discussion of the study are given in Section 5.1. The final $y^{+}$distribution on the smooth surfaces is shown in Figure 10 for the validation study and in Figure 11 for the full scale prediction study. Only a small portion of the plate is shown in Figure 11, as it is $170 \mathrm{~m}$ long in total.

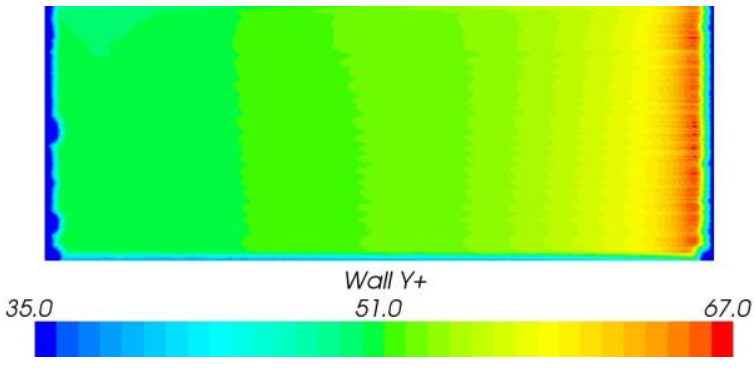

a)

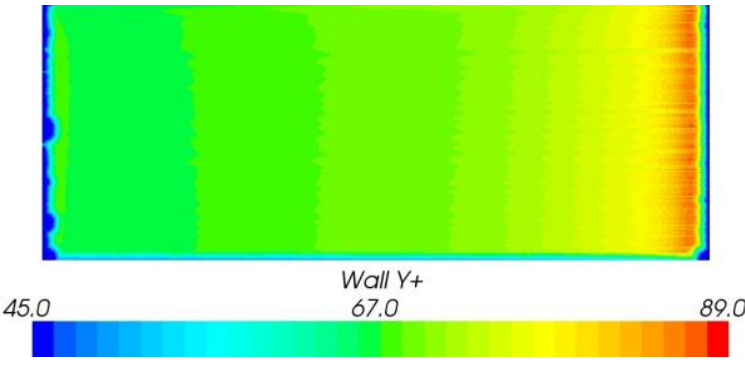

b) 


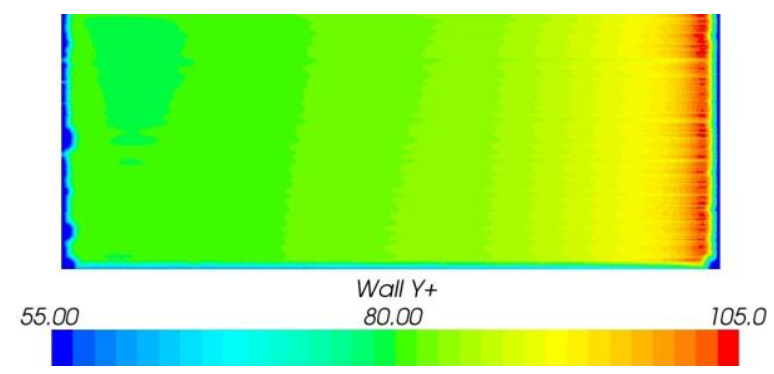

c)

Figure 10. $y^{+}$values on the smooth plates at a) $\operatorname{Re}=2.8 \times 10^{6}$, b) $\left.\operatorname{Re}=4.2 \times 10^{6}, \mathbf{c}\right) \operatorname{Re}=5.5 \times 10^{6}$.

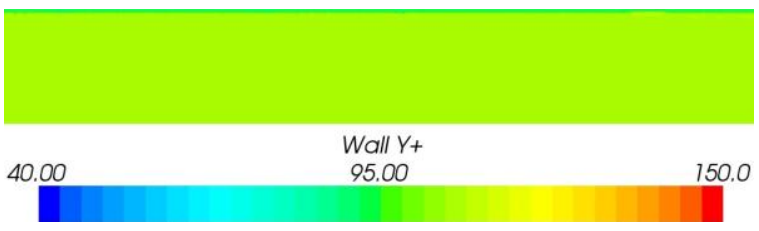

Figure 11. $y^{+}$values on the smooth plate at 13 knots.

\section{RESULTS}

\subsection{Grid dependence tests}

Systematic studies were performed using the surfaces coated with SPC TBT in order to obtain grid independent solutions for both validation and full scale prediction studies.

Firstly, a near-wall grid dependence study was carried out to determine the effect of $y^{+}$on the calculated $C_{F}$ values of both the plate operating at $\operatorname{Re}=2.8 \times 10^{6}$, and the plate which represents the tanker operating at 13 knots. To generate each mesh, the distance of the first grid from the rough wall was gradually changed, whilst keeping all other parameters the same. The results from different simulations, each with a different $y^{+}$value, are shown in Table 2 for the validation study and in Table 3 for the full scale prediction study. The $y^{+}$ values listed represent the modes of the $y^{+}$distribution histograms.

Table 2. $\mathrm{C}_{\mathrm{F}}$ results at different $y^{+}$values for the validation study.

\begin{tabular}{cccc}
\hline$y^{+}$ & Total No. Cells & $\mathrm{C}_{\mathrm{F}}(\mathrm{CFD})$ & \% Experiment \\
\hline 230 & $3.2 \times 10^{6}$ & 0.004026 & 6.42 \\
130 & $3.5 \times 10^{6}$ & 0.003937 & 4.08 \\
50 & $4 \times 10^{6}$ & 0.003776 & -0.19 \\
7.5 & $4.5 \times 10^{6}$ & 0.003494 & -7.65 \\
\hline
\end{tabular}

Table 3. $\mathrm{C}_{\mathrm{F}}$ results at different $y^{+}$values for the full scale prediction study.

\begin{tabular}{ccc}
\hline$y^{+}$ & Total No. Cells & $\mathrm{C}_{\mathrm{F}}(\mathrm{CFD})$ \\
\hline 1350 & $2.8 \times 10^{6}$ & 0.001619 \\
250 & $3.6 \times 10^{6}$ & 0.001595 \\
110 & $4 \times 10^{6}$ & 0.001584 \\
75 & $4.5 \times 10^{6}$ & 0.001580 \\
\hline
\end{tabular}


As demonstrated in Table 2, the solution with the $y^{+}$value of 7.5 deviates significantly from the experimental data, as expected, since standard wall laws can be used only if $y^{+}$values are greater than 30. The results presented in Table 2 demonstrate that the solution with the $y^{+}$ value of 50 was converged fairly well. This resolution was therefore used throughout all cases of the validation study.

It can be seen from Table 3 that the solutions with the $y^{+}$values of 110 and 75 converged well, with little variation in the $C_{F}$ value when using $y^{+}$values of either 110 or 75 . On the other hand, the difference in the total number of cells is half a million between these two resolutions. Therefore, the resolution with the $y^{+}$value of 110 was chosen and used throughout all cases of the full scale prediction study.

Having determined the near-wall mesh resolutions, a grid dependence test for the rest of the domain, including the plate itself, was carried out. The rest of the domain was discretised in four different resolutions; coarse, medium, fine and very fine. The frictional resistance coefficients for each mesh configuration were computed and are given in Table 4 and Table 5 .

The solution for the coarse mesh configuration in the validation study did not converge, and showed very large oscillations. This may be due to the weak resolution of the plate geometry, as well as the free surface and wake. From Table 4 and Table 5 it is evident that the solutions of the fine and very fine meshes converged very well in both the validation and prediction study. Therefore, the fine mesh configuration was selected in all subsequent computations.

Table 4. $\mathrm{C}_{\mathrm{F}}$ results at different mesh configurations for the validation study.

\begin{tabular}{cccc}
\hline Mesh configuration & Total No. Cells & $\mathrm{C}_{\mathrm{F}}(\mathrm{CFD})$ & $\%$ Experiment \\
\hline Coarse & $1.5 \times 10^{6}$ & {[]} & {[]} \\
Medium & $2.5 \times 10^{6}$ & 0.003805 & 0.60 \\
Fine & $4 \times 10^{6}$ & 0.003776 & -0.19 \\
Very Fine & $6 \times 10^{6}$ & 0.003785 & 0.07 \\
\hline
\end{tabular}

Table 5. $C_{F}$ results at different mesh configurations for the full scale prediction study.

\begin{tabular}{ccc}
\hline Mesh configuration & Total No. Cells & $\mathrm{C}_{\mathrm{F}}(\mathrm{CFD})$ \\
\hline Coarse & $1.8 \times 10^{6}$ & 0.001574 \\
Medium & $2.5 \times 10^{6}$ & 0.001576 \\
Fine & $4 \times 10^{6}$ & 0.001584 \\
Very Fine & $5.5 \times 10^{6}$ & 0.001584 \\
\hline
\end{tabular}

\subsection{Validation study}

\subsubsection{Frictional resistance coefficients}

Table 6, Table 7 and Table 8 demonstrate the frictional resistance coefficients computed by CFD and obtained by experiments for five different coatings, as well as a smooth surface, at $\operatorname{Re}=2.8 \times 10^{6}, \operatorname{Re}=4.2 \times 10^{6}$ and $\operatorname{Re}=5.5 \times 10^{6}$, respectively. 
Table 6. The comparison of $\mathrm{C}_{\mathrm{F}}$ values at $\mathrm{Re}=2.8 \times 10^{6}$.

\begin{tabular}{lccc}
\hline Surface & $\mathrm{C}_{\mathrm{F}}(\mathrm{CFD})$ & $\mathrm{C}_{\mathrm{F}}$ (Experiment) & Difference (\%) \\
\hline Smooth & 0.003632 & 0.003605 & 0.74 \\
Silicone 1 & 0.003715 & 0.003666 & 1.35 \\
Silicone 2 & 0.003729 & 0.003663 & 1.81 \\
Ablative Copper & 0.003722 & 0.003701 & 0.58 \\
SPC Copper & 0.003736 & 0.003723 & 0.35 \\
SPC TBT & 0.003776 & 0.003783 & -0.19 \\
\hline
\end{tabular}

Table 7. The comparison of $\mathrm{C}_{\mathrm{F}}$ values at $\mathrm{Re}=4.2 \times 10^{6}$.

\begin{tabular}{lccc}
\hline Surface & $\mathrm{C}_{\mathrm{F}}(\mathrm{CFD})$ & $\mathrm{C}_{\mathrm{F}}$ (Experiment) & Difference $(\%)$ \\
\hline Smooth & 0.003411 & 0.003418 & -0.21 \\
Silicone 1 & 0.003528 & 0.003499 & 0.82 \\
Silicone 2 & 0.003545 & 0.003540 & 0.14 \\
Ablative Copper & 0.003536 & 0.003507 & 0.84 \\
SPC Copper & 0.003553 & 0.003526 & 0.78 \\
SPC TBT & 0.003603 & 0.003611 & -0.23 \\
\hline
\end{tabular}

Table 8. The comparison of $\mathrm{C}_{\mathrm{F}}$ values at $\mathrm{Re}=5.5 \times 10^{6}$.

\begin{tabular}{lccc}
\hline Surface & $\mathrm{C}_{\mathrm{F}}(\mathrm{CFD})$ & $\mathrm{C}_{\mathrm{F}}$ (Experiment) & Difference $(\%)$ \\
\hline Smooth & 0.003185 & 0.003226 & -1.26 \\
Silicone 1 & 0.003460 & 0.003374 & 2.54 \\
Silicone 2 & 0.003481 & 0.003426 & 1.60 \\
Ablative Copper & 0.003470 & 0.003401 & 2.04 \\
SPC Copper & 0.003491 & 0.003438 & 1.55 \\
SPC TBT & 0.003551 & 0.003500 & 1.45 \\
\hline
\end{tabular}

As can be seen from Tables 6, 7 and 8, the computed $\mathrm{C}_{\mathrm{F}}$ values of the smooth and coated surfaces are in fair agreement with the experimental data. The differences are slightly higher at $\operatorname{Re}=5.5 \times 10^{6}$, though the differences at all of the Reynolds numbers can be considered to be negligible since the experimental uncertainty in $C_{F}$ is given as $\pm 5 \%$ for $\operatorname{Re}=2.8 \times 10^{6}$ and $\pm 2 \%$ for $\operatorname{Re}=5.5 \times 10^{6}$ (Schultz, 2004).

The computed $\mathrm{C}_{\mathrm{F}}$ values of the silicone coatings have relatively higher differences from the experimental data at $\operatorname{Re}=2.8 \times 10^{6}$, which is thought to be due to the slight deviation of the roughness functions from the proposed roughness function model at this Reynolds number, as shown in Figure 4.

The best agreement between the computed values and the experimental data is achieved at $\mathrm{Re}$ $=4.2 \times 10^{6}$. In this case, the roughness functions at the corresponding Reynolds number correlate remarkably well with the roughness function model given in Figure 4.

Although the differences in the roughness amplitude parameters of the coatings are very small, the proposed wall law and CFD model is able to accurately take this effect into account. As expected, the computed $\mathrm{C}_{\mathrm{F}}$ values increase with increases in the roughness amplitude parameters, and the frictional resistance coefficients decrease with increasing speed. 
It should be noted that Table 2 includes four sets of results previously determined by, and discussed in, Demirel et al. (2014) using the same methodology as in this study.

\subsubsection{Roughness Reynolds numbers}

Considering $\mathrm{Eq} 6$, the value of $k^{+}$depends on the friction velocity $U_{\tau}$. For this reason, the roughness Reynolds numbers are not uniform within the surface, instead varying depending on the location on the plate. Due to the fact that the software is able to obtain the $U_{\tau}$ distribution on the plate in question, a user defined variable, $k^{+}$, can be created, and so the distribution of $k^{+}$was evaluated on the plates for each particular case. Histograms were then created using the distribution data. Figure 12 shows the $k^{+}$distributions on the plates coated with SPC TBT at three different Reynolds numbers as an example.

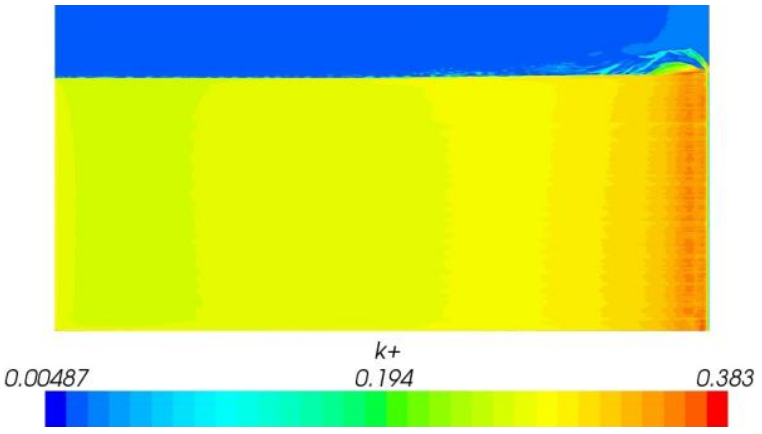

a)

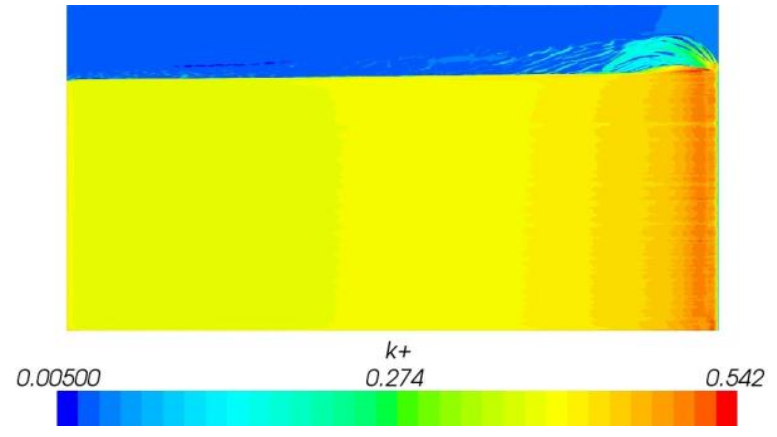

b)

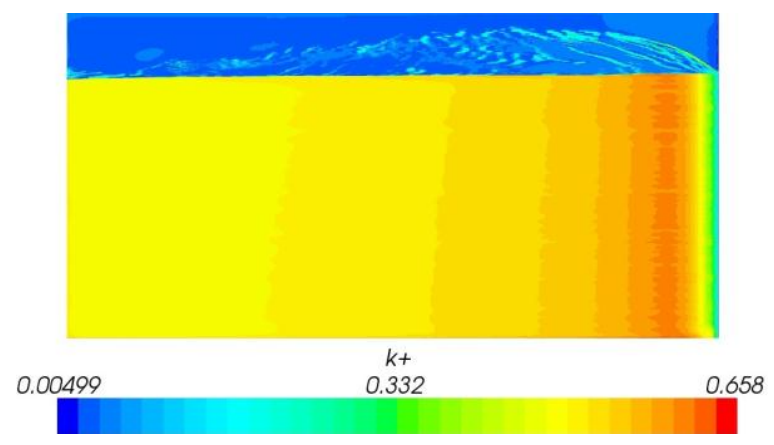

c)

Figure 12. $k^{+}$distribution on the plates coated with SPC TBT at a) $\left.\operatorname{Re}=2.8 \times 10^{6}, \mathbf{b}\right) \operatorname{Re}=4.2 \times 10^{6}$,

$$
\text { c) } \operatorname{Re}=5.5 \times 10^{6} \text {. }
$$

The most frequently occurring roughness Reynolds numbers were obtained from the software and compared with those calculated with Equation 9 using the experimental data. The resulting comparisons are shown in Figure 13. 


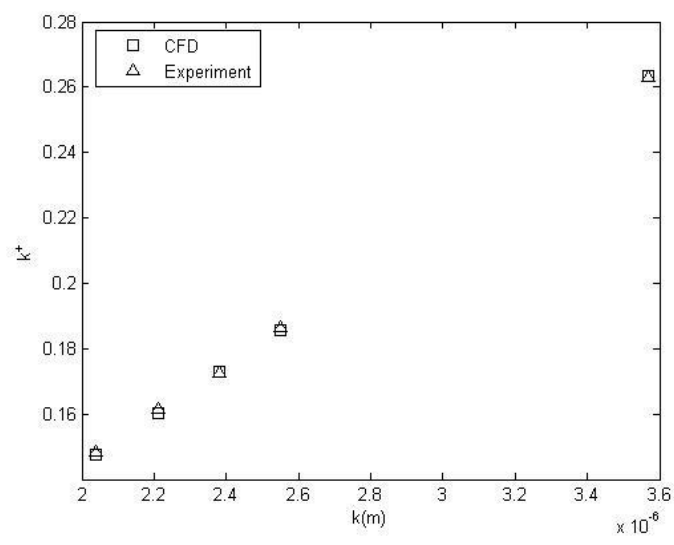

a)

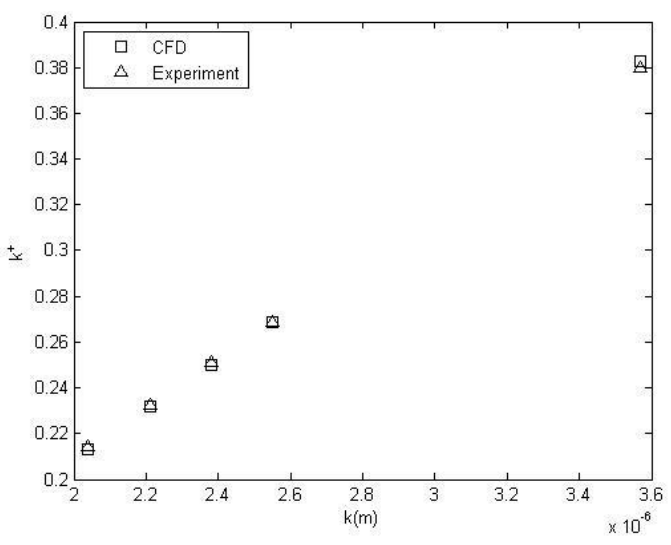

b)

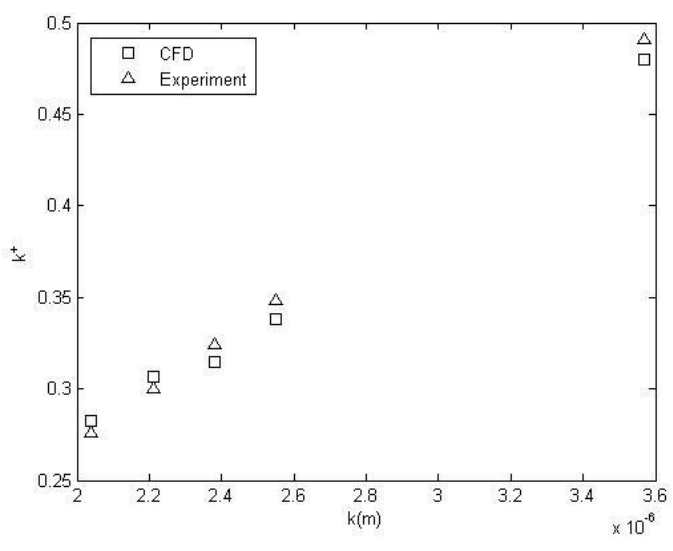

c)

Figure 13. Roughness heights vs. roughness Reynolds numbers at a) $\operatorname{Re}=2.8 \times 10^{6}$, b) $\operatorname{Re}=4.2 \times 10^{6}$

c) $\operatorname{Re}=5.5 \times 10^{6}$.

The computed roughness Reynolds numbers showed reasonable agreement with those obtained from the experimental data. The average differences are $0.3 \%, 0.35 \%$ and $2.5 \%$ at $\operatorname{Re}=2.8 \times 10^{6}, \operatorname{Re}=4.2 \times 10^{6}$ and $\operatorname{Re}=5.5 \times 10^{6}$, respectively. These results prove that the roughness Reynolds numbers can be computed accurately by means of a CFD approach for a given roughness height.

Accurate computation of $k^{+}$values is of paramount importance because the imposed roughness function model provides the required $\Delta U^{+}$based on the computed $k^{+}$value, shown in Figure 4, leading to the accurate computation of $\mathrm{C}_{\mathrm{F}}$ values. The computed $k^{+}$values have relatively higher differences from the experimental data at $\operatorname{Re}=5.5 \times 10^{6}$. This may be one of the reasons for the slight differences between the computed and experimentally obtained $\mathrm{C}_{\mathrm{F}}$ values at this speed shown in Table 8 .

\subsection{Prediction of $C_{F}$ values at full scale}

Table 9 shows the predicted frictional resistance coefficients of a handymax tanker coated with several antifouling coatings at an operational speed of 13 knots. It also gives the percentage increase in frictional resistance coefficients with respect to the smooth condition. 
Table 9. The comparison of $\mathrm{C}_{\mathrm{F}}$ values at full scale at 13 knots.

\begin{tabular}{lcc}
\hline Surface & $\mathrm{C}_{\mathrm{F}}(\mathrm{CFD})$ & Increase in $\mathrm{C}_{\mathrm{F}}(\%)$ \\
\hline Smooth & 0.001494 & - \\
Silicone 1 & 0.001550 & 3.77 \\
Silicone 2 & 0.001558 & 4.32 \\
Ablative Copper & 0.001554 & 4.05 \\
SPC Copper & 0.001562 & 4.59 \\
SPC TBT & 0.001585 & 6.10 \\
\hline
\end{tabular}

As seen in Table 9, the percentage increase in frictional resistance coefficients due to the antifouling coatings' roughness varies between 3.77 to $6.10 \%$. SPC TBT leads to the highest increase in $\mathrm{C}_{\mathrm{F}}$ values as expected due to its relatively higher roughness amplitude parameters. However, the reader should note that the evaluated $C_{F}$ values and the percentage increases are due to the initial roughness of the coatings, and the increase in $\mathrm{C}_{\mathrm{F}}$ over time varies depending on the duration of sea exposure and the time-dependent drag performance of each coating.

\section{CONCLUSIONS}

A CFD model for the prediction of the effect of antifouling coatings on frictional resistance has been proposed. The Colebrook-type roughness function of Grigson (1992) was employed in the wall-function of the solver and a validation study was carried out to examine the validity of the proposed model. The frictional resistance coefficients and roughness Reynolds numbers for five antifouling coatings and a smooth surface were computed using CFD simulations. The results of the validation study were in fairly good agreement with the experimental data, with the differences between CFD and the experiment ranging from 0.14 $2.54 \%$ for $\mathrm{C}_{\mathrm{F}}$ and $0.3-2.5 \%$ for $k^{+}$. It has been shown that surface roughness can be modelled by employing modified wall laws within the wall functions. It may be concluded that the proposed approach is capable of predicting the roughness effects of antifouling coatings on frictional resistance. Hence, the increases in the $C_{F}$ values of a ship due to different types of antifouling coatings were predicted using the proposed CFD model.

It should be borne in mind that this study's aim was to propose a robust CFD model, rather than a case-based model, to predict the frictional resistance of antifouling coatings. For this reason, an appropriate representative roughness function model was employed in spite of the slight discrepancies between the individual roughness function values and the model. The insignificant differences between the computed $\mathrm{C}_{\mathrm{F}}$ values and the experimental data are therefore thought to be due to the aforementioned insignificant scatter.

The main advantage of the proposed model is that it enables the use of a simple roughness length scale, according to the surface roughness measurements, rather than equivalent sandgrain roughness height, which is a hydrodynamically obtained parameter.

Additionally, the critical points of the numerical modelling of roughness effects on flow have been highlighted in this paper. It has also been demonstrated that the existing roughness function model of the CFD software can be modified according to the experimental data and that the effects of different types of roughness on flow can be predicted in this way.

Future plans are to utilise this approach and employ a new wall law to simulate fouling and to predict the effect of fouling on frictional resistance. A piece of future work may be the investigation of the validity of the wall function approach to simulate the surface roughness 
on ship hulls, rather than on flat plates, since the pressure gradient varies significantly along ship hulls.

A final point to note is that while CFD provides accurate results in order to model roughness effects on frictional resistance, experimental data and further study into the correlation between roughness and drag are a necessity for the development of accurate CFD prediction methods.

\section{ACKNOWLEDGEMENTS}

The authors gratefully acknowledge that the research presented in this paper was partially generated as part of the EU funded FP7 project FOUL-X-SPEL (Environmentally Friendly Antifouling Technology to Optimise the Energy Efficiency of Ships, Project number 285552, FP7-SST-2011-RTD-1).

It should be noted that the results were obtained using the EPSRC funded ARCHIE-WeSt

High Performance Computer (www.archie-west.ac.uk). EPSRC grant no. EP/K000586/1.

\section{REFERENCES}

ANSYS (2011). FLUENT Theory Guide, Release 14.

Candries, M. (2001). Drag, boundary-layer and roughness characteristics of marine surfaces coated with antifoulings, PhD Thesis, Department of Marine Technology, University of Newcastle-upon-Tyne, UK.

Candries, M., Atlar, M., Mesbahi E., Pazouki K. (2003). The measurement of the drag characteristics of tin-free self-polishing co-polymers and fouling release coatings using a rotor apparatus. Biofouling, 1029-2454 19(1), 27-36 Suppl.1.

Cortana (2013). Description of Drag. [Online] Available from: http://www.cortana.com/Drag_Description.htm. [Accessed: 24th November 2013]

CD-ADAPCO (2012). User Guide STAR-CCM+, Version 7.02.011.

Cebeci, T. and Bradshaw, P. (1977). Momentum Transfer in Boundary Layers. Washington, DC, Hemisphere Publishing Corp.; New York, McGraw-Hill Book Co., 1977.

Date, J.C., Turnock, S.R. (1999). A study into the techniques needed to accurately predict skin friction using RANS solvers with validation against Froude's historical flat plate experimental data. Southampton, UK, University of Southampton, 62pp. (Ship Science Reports, (114) ).

Demirel, Y.K., Khorasanchi, M., Turan, O., Incecik, A. (2013a). A parametric study: hull roughness effect on ship frictional resistance. In International Conference on Marine Coatings. 18th April 2013. London, UK: pp. 21-28.

Demirel, Y.K., Khorasanchi, M., Turan, O. and Incecik, A. (2013b). On the importance of antifouling coatings regarding ship resistance and powering. In 3rd International 
Conference on Technologies, Operations, Logistics and Modelling for Low Carbon Shipping. 9 - 10 September 2013, London, UK.

Demirel, Y.K., Khorasanchi, M., Turan, O. and Incecik, A. (2014). CFD approach to resistance prediction as a function of roughness. In Transport Research Arena Conference 2014. 14 - 17 April 2014, Paris La Défense, France.

Ferziger, J.H., Peric, M. (2002). Computational Methods for Fluid Dynamics, $3^{\text {rd }}$ Edition. Springer, Berlin, Germany.

Granville, P.S. (1987). Three indirect methods for the drag characterization of arbitrarily rough surfaces on flat plates. Journal of Ship Research. 31: 70-77.

Grigson, C. W. B. (1992). Drag Losses of New Ships Caused by Hull Finish. Journal of Ship Research, 36: 182-196.

ITTC. (2005). ITTC - Recommended Procedures and Guidelines : Testing and Extrapolation Methods, Propulsion, Performance, Predicting Powering Margins. ITTC.

ITTC. (2011a). Specialist Committee on Surface Treatment - Final report and recommendations to the $26^{\text {th }}$ ITTC.

ITTC. (2011b). ITTC - Recommended Procedures and Guidelines : Practical Guidelines for Ship CFD Application. ITTC.

Izaguirre-Alza, P., Pérez-Rojas, L., and Núñez-Basáñez, J.F. (2010). Drag reduction through special paints coated on the hull. In International Conference on Ship Drag Reduction SMOOTH-SHIPS. 20 - 21 May 2010, Istanbul, Turkey.

Kempf, G. (1937). On the effect of roughness on the resistance of ships. Trans. Institution of Naval Architects 79: 109-119.

Khor, Y.S., Xiao, Q. (2011). CFD simulations of the effects of fouling and antifouling. Ocean Engineering 38: 1065-1079.

Lackenby, H. (1962). Resistance of ships, with special reference to skin friction and hull surface condition. Proc Inst Mechl Eng 176: 981-1014.

Leer-Andersen, M., Larsson L. (2003). An experimental/numerical approach for evaluating skin friction on full-scale ships with surface roughness. Journal of Marine Science and Technology (8): 26-36.

Millikan, C.M. (1938). A critical discussion of turbulent flows in channels and circular tubes. Proc. 5th Int. Congr. Appl. Mechanics, Cambridge, MA, 386-392.

Milne, A. (1990). Roughness and drag from the marine paint chemist's viewpoint. Marine Roughness and Drag Workshop, London.

Nikuradse, J. (1933). Laws of Flow in Rough Pipes, NACA Technical Memorandum 1292. 
RAEng. (2013). Future ship powering options. [Online] July 2013. Available from: https://www.raeng.org.uk/news/publications/list/reports/Future_ship_powering_options_ report.pdf. [Accessed: 1st December 2013]

Schlichting, H. (1979). Boundary-Layer Theory. 7th ed., McGraw-Hill, New York.

Schubauer, G.B., Tchen, C.M. (1961). Turbulent flow. Princeton University Press, New Jersey, USA.

Schultz, M.P. (2004). Frictional resistance of antifouling coating systems. ASME J. Fluids Eng. 126: 1039-1047.

Schultz, M.P. (2007). Effects of coating roughness and biofouling on ship resistance and powering. Biofouling, 23 (5): 331-341.

Schultz, M.P., Swain, G.W. (2000). The influence of biofilms on skin friction drag. Biofouling 15: 129-139.

Schultz M.P. and Flack, K.A. (2007). The rough-wall turbulent boundary layer from the hydraulically smooth to the fully rough regime. J Fluid Mech 580:381 - 405.

Taylan, M. (2010). An overview: effect of roughness and coatings on ship resistance. International Conference on Ship Drag Reduction SMOOTH-SHIPS, Istanbul, Turkey.

Tezdogan, T., Demirel, Y.K. (2014). An overview of marine corrosion protection with a focus on cathodic protection and coatings. Brodogradnja/Shipbuilding 65 (2): 49-59.

van Manen, J. D., van Oossanen, P. (1988). Resistance. In: Lewis, E.V. (ed.). Principles of Naval Architecture. Second Revision. Volume II: Resistance, Propulsion and Vibration. Jersey City, NJ: The Society of Naval Architects and Marine Engineers. 